The message of secondary prevention and harm minimisation is just as important, but more difficult. The seminar highlighted how little physicians and psychiatrists were seen to have an educational and advisory role; Rabbi Julia Neuberger specifically singled out general practitioners.

Drug abuse is one of those issues that everyone feels they can be opinionated about often with a very unclear understanding of their psychological and physical effects. This attitude perhaps reflects a more general uncertainty about where the primary responsibility for tackling drug abuse lies. For instance, is the Home Office's position as lead agency with the Department of Health playing a subsidiary role appropriate? It seems that there are shortcomings in the response of doctors to this issue and a great need for both psychiatrists and physicians to take a higher profile role in educating and advising about the hazards of substance misuse.

\title{
Residential scientific conference on the Reed Report and the management of the mentally disordered offender in the community
}

\author{
TOM BuRns, Chairman, Social, Community and Rehabilitation Section
}

Over 250 psychiatrists attended a conference in Jersey from 26-28 November 1992, arranged by the Social, Community and Rehabilitation Section of the College in association with the General and Forensic Sections to review current practice and research on the mentally disordered offender (MDO). The three days contained two plenary sessions, a parallel workshop session, and a short paper session.

The first session-'The Response to the Reed Report' - was the day before the report (1992) was presented to the House of Commons. The report's basic principles were outlined by Dr Derek Chiswick from Edinburgh who presented a forensic psychiatrist's response. Despite the aim to treat the MDO within the health care system, less than $40 \%$ of providers and $30 \%$ of purchasers have diversion from custody schemes in their current or proposed business plans. Professor James Watson, Dr Janet Parrott and Dr Philip Brown from United Medical and Dental Schools described a local project to improve the procedures for transferring mentally ill offenders from Brixton Prison to NHS facilities. They emphasised the importance of a "balance of competence" between forensic psychiatrists and the general psychiatrists who will be responsible for most of the work.

The practicalities of dealing with MDOs in a community setting were outlined by Dr Marilyn Mitchell whose Continuing Care Service Team (developed within the rehabilitation service) had achieved high levels of supervision and a significant reduction in admissions but found early intervention with this small group of potentially dangerous patients posed serious ethical dilemmas.

Dr Reed rounded off the session by reaffirming the principles on which the report was grounded, detailing the process by which consultation documents were produced and reviewed. He stressed the time frame of the report's resource implications-not simply because of their financial burden but for the adequate academic and training input needed for the new consultants recommended.

The second plenary session was devoted to compulsory treatment in the community. Professor Robert Bluglass' presentation 'Compulsory Care in the Community-do we need it' considered the College's recent working party on compulsory treatment orders (CTOs) in context from the first British Association of Social Workers proposal included in the Government's 1974 Green Paper through to the College's 1987 discussion document 'Community Treatment Orders'. The group believed that we did need some form of CTO for patients with established histories of relapse associated with poor medication compliance after successful responses to compulsory treatment. Safeguards would be similar to those provided for Section 3 of the 1983 Mental Health Act with recall to hospital if the patient failed to comply with the conditions of supervision. The order would be time limited although the precise duration along with a number of other details remain under discussion. 
Dr Charlie Brooker, Regional Nurse (Research), Trent Health, challenged this conclusion. Compliance could be substantially improved in the target group of psychotic patients if community psychiatric nurses were better trained. Some of the pressure for a CTO may come from a failure to target adequately trained services on the seriously mentally ill. Such skills, he said, would not be obtained from within traditional nurse training.

Dr Tom Sensky compared 'extended leave' patients, those 'nominated' as being suitable for a CTO and a control group judged not to need it. He concluded that reliable, clinical identification of the target group was possible. American experience of CTOs, however, was not universally reassuring.

This complex session was made even more challenging by Phill Fennell, Lecturer in Law at Cardiff. After a detailed overview of historical precedents to a CTO and their often completely unanticipated consequences, he responded to the draft proposals outlined by Professor Bluglass. The Mental Health Review Tribunal is, he contended, unique in that the burden of proof is on the patient or his advocate to establish why he should be set free. Given this unusual configuration of the MHA Tribunal he felt that the proposed CTO could be in conflict with Article 5 of the European Convention on Human Rights if a patient who had not, as yet, deteriorated were to be recalled to hospital.

Considerable concern was expressed that CTOs should not be seen as a cheap alternative to comprehensive community services. The attitudes of the voluntary sector and users groups were clearly crucial but confusing at present and it was important not to risk good relations with them for a numerically very small patient group.

The conference was marked by the lively debate engendered by the differing viewpoints of the three sections on issues of intense importance to all of them. The presence of a large group of SRs for such a meeting also supplied vigour.

\section{Reference}

Review of Health and Social Services for Mentally Disordered Offenders and Others Requiring Similar Services. Final Summary Report. HMSO, London, 1992. Command Number 2088. $£ 12.40$.

\title{
European Association for Mental Health in Mental Retardation*
}

\author{
N. BouRAS, Division of Psychiatry, Guy's Hospital, London SE1 9RT
}

Delegates from 13 European countries attended the inaugural meeting of the European Association for Mental Health in Mental Retardation in The Netherlands.

The theme of the conference was current advances, practices and service developments for people with mental retardation and psychiatric disorders. Despite the fact that most European countries haveadopted the principles of "normalisation" and "social integration" for services for people with mental retardation, great differences still exist between them in their approach to care. The differences are mainly associated with organisational difficulties, professional ideology and approach and cultural aspects and beliefs.

With the exception of very few countries where there is an organised system of services for people

Conference held on 8-9 October 1992 in Veldhoven, The Netherlands. with mental retardation and psychiatric disorders, most European countries have not achieved an optimum level of care. Instead, there have been rather isolated initiatives, pioneered either by individuals or organisations. The newly formed European Association aims to ameliorate the problems through international collaboration, joint programmes, conferences and research projects. The experience gained from North America through the activities of the National Association for the Dually Diagnosed, whose representatives were also present, would be taken into consideration and would be beneficial.

The members of the Executive Committee are A. Dosen (Netherlands), K. Day (UK), W. Verhoeven (Netherlands), C. Gaedt (Germany) and M. Van Wallenghem (Belgium). Further information can be obtained from: Dr A. Dosen, Nieuw Spraeland, Postbus 5029, 5800 GA Venray, Netherlands. 